\title{
EL MITO Y SU INFLUENCIA EN EL VÍNCULO EMOCIONAL ENTRE EL ESPECTADOR Y LA OBRA EN EL TEATRO MUSICAL DEL SIGLO DE ORO: RECURSOS MITOLÓGICOS EN ÍCARO Y DÉDALO DE MELCHOR FERNÁNDEZ DE LEÓN ${ }^{1}$
}

\author{
Ieva Emilija Rozenbergaite \\ (Universidad Complutense de Madrid) \\ ievaemir@ucm.es
}

\section{RESUMEN}

El presente artículo propone un análisis del tratamiento de los recursos mitológicos en Ícaro y Dédalo, de Melchor Fernández de León, y su posible influencia en el nexo psíquico entre el público y la obra. El método de trabajo consiste en la aplicación de la noción de «distancia psíquica», un concepto filosófico orientado al involucramiento emocional en un momento de apreciación estética. Con la ayuda de esta herramienta, se examinan los impulsos psíquicos producidos por el uso de la materia mitológica en la elaboración del argumento, los personajes y los símbolos de la zarzuela aurisecular. El objetivo final del trabajo es, sirviéndose del ejemplo de Ícaro y Dédalo, detectar los reflejos de la mentalidad de la sociedad del siglo XVII latentes en la predilección por la temática mitológica en el teatro musical de la época.

PALABRAS CLAVE: Ícaro y Dédalo, Melchor Fernández de León, mitología, Siglo de Oro, teatro musical, distancia psíquica

\section{THE MYTH AND ITS INFLUENCE ON THE EMOTIONAL BOND BETWEEN THE SPECTATOR AND THE WORK IN THE MUSICAL THEATRE OF THE GOLDEN CENTURY: MYTHOLOGICAL RESOURCES IN ICARUS AND DAEDALUS BY MELCHOR FERNÁNDEZ DE LEÓN}

\begin{abstract}
The present article proposes an analysis of the treatment of the mythological resources in Melchor Fernández de León's Ícaro y Dédalo and its possible influence over the psychic nexus between the audience and the zarzuela. The work method consists in the application of the notion of the 'Psychic Distance', a philosophical concept

${ }^{1}$ Este trabajo se incluye en el marco del proyecto de investigación Fiestas teatrales en el Coliseo del Buen Retiro (1650-1660): Catalogación, estudio, edición crítica y recreación virtual aprobado por el Ministerio de Ciencia, Innovación y Universidades con la referencia PGC2018-098699-B-I00.
\end{abstract}


focused on the emotional engagement during the moment of aesthetic appreciation. With the help of this tool are examined the psychic impulses produced by the usage of mythological material in the elaboration of the argument, the characters and the symbols of the zarzuela. The ultimate goal of this work is to detect reflections of the mentality of the 17 th century society laying in the predilection for the mythological subject in the musical theatre by using the example of Ícaro y Dédalo.

KEY WORDS: Ícaro y Dédalo, Melchor Fernández de León, mythology, Golden Age, musical theatre, Psychic Distance

Aunque la zarzuela del siglo XVII puede presumir de determinadas particularidades que le otorgan una autonomía indudable ante el género músico-teatral reinante en el resto de la Europa de la época, la ópera ${ }^{2}$, tampoco se puede obviar el amplio abanico de afinidades que se encuentran entre ambas manifestaciones artísticas. Evidentemente, uno de los rasgos más universales de las zarzuelas auriseculares son sus argumentos mitológicos, una tendencia en el teatro musical europeo de entonces. Siendo un atlas de condiciones humanas, el mito está abierto a un sinfín de temas y variaciones, lo cual lo convierte en instrumento dramático perfecto, capaz de transmitir toda una gama de registros existenciales. En el contexto del teatro áureo Margaret R. Greer destaca tres sustratos principales de las obras mitológicas: el mito del poder, el mito universal y el mito político ${ }^{3}$. Intrigada por la polisemia que nos proponen textos de esta temática y su arraigamiento en los géneros músico-teatrales del momento, me he planteado el objetivo de reflexionar sobre si la posible influencia de los argumentos mitológicos en el vínculo emocional entre el público y la representación tendía a ser igual de complicada y polifacética.

En mi artículo «La distancia psíquica como herramienta para analizar el teatro musical del Siglo de Oro ${ }^{4} »$ presento una propuesta de investigación sobre el espectador aurisecular desde una perspectiva esteticista. Mi sugerencia se basa en un tratamiento de los tres planos de la convicción dramática -el sonoro, el visual y el textual- vía la aplicación del concepto de distancia psíquica - una idea recurrente en numerosas doctrinas filosóficas a partir del surgimiento de la famosa Crítica del juicio de Kant y

${ }^{2}$ Las principales diferencias entre la zarzuela y la ópera del siglo XVII -las que considero residir en el modo de organizar las intervenciones musicales en los dos géneros- se comentan en mi artículo "La distancia psíquica como herramienta para analizar el teatro musical del Siglo de Oro”, Diablotexto Digital, 7 (Universitat de València, 2020), 41-52. <https://ojs.uv.es/index.php/diablotexto/article/view/16718/15497> (consultado el 26 de julio de.2020). https://doi.org/10.7203/diablotexto.7.16718

${ }^{3}$ El explícito comentario de Greer sobre los sustratos de las obras mitológicas del Siglo de Oro se puede leer en "Myths and Texts in the Courtly Fiesta", La estatua de Prometeo, ed. M. Rich Greer (Kassel: Kassel Edition Reichenberger, 1986), 133-187.

${ }^{4}$ I. E. Rozenbergaite, "La distancia psíquica como herramienta para analizar el teatro musical del Siglo de Oro", 33-53. 
focalizada en el involucramiento emocional en un momento de apreciación estética ${ }^{5}$. A través de este tipo de análisis pretendo desentrañar ciertos procesos emotivo-sociales que tenían un gran impacto sobre el desarrollo de las artes escénicas ${ }^{6}$. El hecho de que los argumentos mitológicos formen parte de un género tan heterogéneo como la zarzuela me impulsa a acercarme a los posibles estímulos emocionales e intelectuales que ejercían sobre el público desde la misma perspectiva de la distancia psíquica.

Ícaro y Dédalo, de Melchor Fernández de León, es una zarzuela en tres actos estrenada el 25 de agosto de 1684 en el Coliseo del Buen Retiro con ocasión de la festividad de San Luis de los Franceses, día del santo de la reina $\mathrm{M}^{\mathrm{a}}$ Luisa de Orleans. Su música fue compuesta por nada menos que el maestro Juan Hidalgo, uno de los nombres más insignes del teatro musical del siglo XVII en la Península. Aunque tanto el título de la obra como el nombre de Fernández de León se pueden encontrar en numerosos estudios relacionados con el teatro áureo, normalmente son menciones breves y poco exhaustivas, evidentemente, con algunas excepciones, entre las que destaca sobre todo Melchor Fernández de León: la sombra de un dramaturgo, de Gerardo Fernández San Emeterio, un libro publicado en 2011 y que vino a llenar un enorme hueco en las investigaciones sobre la vida y la obra del autor de Ícaro y Dédalo. Considerada la importancia que tenían las representaciones del Coliseo del Buen Retiro para la cultura aurisecular, además de la inmensa carga filosófica que lleva uno de los mitos más populares de todos los tiempos, el de Ícaro, he decidido que esta obra de Fernández de León podría ser un perfecto ejemplo de la interacción emocional e intelectual entre el público y una zarzuela de temática mitológica. Por lo tanto, el presente artículo posee una doble intención: reflexionar sobre el influjo del mito en el efecto producido por la representación y dar más visibilidad a la obra de «uno de los más excelentes genios ${ }^{7} \gg$ de la corte madrileña.

\section{SIGNIFICADO DEL MITO}

Antes de empezar con el comentario de los elementos mitológicos de Ícaro y Dédalo veo necesario establecer la noción de mito que se tendrá en cuenta en el análisis posterior. Para este propósito considero muy adecuada la observación de la filósofa estadounidense Susanne K. Langer que aparece en su libro Philosophy in a New Key, dedicado a un estudio esteticista de la naturaleza del arte:

\footnotetext{
${ }^{5}$ La noción de distancia psíquica (Psychic Distance), o «desapego artístico» (Artistic Detachment), entendidos como el nivel del involucramiento emocional, se explica más detenidamente en ibídem, 3441, y, sobre todo, en un fabuloso estudio de Steve Odin, dedicado enteramente al concepto, Artistic Detachment in Japan and the West: Psychic Distance in Comparative Aesthetics (University of Hawaii Press, 2001).

${ }^{6}$ I. E. Rozenbergaite, "La distancia psíquica como herramienta para analizar el teatro musical del Siglo de Oro”, 50.

${ }^{7}$ En el capítulo "Uno de los más excelentes genios de esta corte’: Melchor Fernández de León“, Fernández San Emeterio [2011: 11] señala como fuente de la denominación la Gaz̧eta de Madrid de diciembre de 1678 .
} 
Myth, [...] at least at its best, is a recognition of natural conflicts, of human desire frustrated by non-human powers, hostile oppression, or contrary desires; it is a story of the birth, passion, and defeat by death which is man's common fate. Its ultimate end is not wishful distortion of the world, but serious envisagement of its fundamental truths; moral orientation, not escape ${ }^{8}$.

Como podemos ver, Langer incide en que las tramas mitológicas son metáforas y alegorías de la realidad humana y de ningún modo una alteración suya que la transforma en espejismo de un mundo mejor. La filósofa lo explica de la siguiente manera:

In short, the fairytale is a form of «wishful thinking», and the Freudian analysis of it fully explains why it is perennially attractive, yet never believed by adults even in the telling. Myth, on the other hand, whether literally believed or not, is taken with religious seriousness, either as historic fact or as a «mystic» truth. Its typical theme is tragic, not Utopian; and its personages tend to fuse into stable personalities of supernatural character.

Es decir, la mitología representa un sistema de símbolos orientado a reflejar las leyes del dramático orden universal que conserva nuestros miedos, deseos, sueños, esperanzas y desilusiones, y la única utopía que reside en ella es la misma que se oculta en nuestras propias creencias en la eternidad después de la muerte -Joseph Campbell define el fenómeno como «clue to the spiritual potentialities of the human life" »- A pesar de estar habitado por seres sobrenaturales, el mito no pretende ofrecernos una imagen de un mundo más justo y menos confuso como lo hacen los cuentos de hadas ${ }^{10}$. El mito no niega nuestros temores, sino al revés: de cierta manera les da validez y nos ayuda a sublimarlos al traspasarlos a un universo estético -en forma de espectáculo teatral en el caso de Ícaro y Dédalo-, ya que los héroes mueren en accidentes trágicos como Faetón, Adonis o el propio Ícaro, son condenados a un sufrimiento eterno como Prometeo o Sísifo, pierden a sus seres queridos como Dédalo, Orfeo o Medea, etc. Por ende, las tramas mitológicas no suelen proponernos ilusiones de una duradera

${ }^{8}$ Susanne K. Langer, Philosophy in a New Key, Harward University Press, 1957, 143.

9 Joseph Campbell, The Power of Myth, EE. UU., Anchor Edition, [1988] 1991, 12.

${ }^{10}$ Campbell, a diferencia de Langer, no separa tan rigurosamente los cuentos de hadas y los mitos antiguos, dado que los dos géneros comparten imagenes arquetípicas, en las que repercute el inconsciente colectivo. En The Power of Myth (111-112) el estudioso incluso califica los cuentos de hadas de la «mitología para niños». No obstante, la línea divisoria que él pone entre ambos tipos de historias coincide, en gran parte, con la opinión de Langer: «Fairy tales are told for entertainment. You've got to distinguish between the myths that have to do with the serious matter of living life in terms of the order of society and of nature, and of stories with some of those same motifs that are told for entertainment».

Sin embargo, en cuanto al final feliz que podemos encontrar en ellos Campbell lo comenta así: «The happy ending of the fairy tale, the myth, and the divine comedy of the soul, is to be read, not as a contradiction, but as a transcendence of the universal tragedy of man. The objective world remains what it was, but, because of a shift of emphasis within the subject, is beheld as though transformed» (The Hero with a Thousand Faces, ([1949] 2004: 47). De ahí que, el mitólogo recalca el hecho de que los reflejos del orden universal también se transparentan en los cuentos de hadas, aunque con distinto énfasis. 
felicidad terrestre como un matrimonio idílico de la bella durmiente o la Cenicienta. A la inversa, ellas nos hacen conscientes de las pasiones, los deslices y la violencia intrínsecos a la naturaleza humana, sin disimular las terribles consecuencias que los suelen acompañar ${ }^{11}$.

Sin embargo, la negación del escape de la realidad mediante el mito, la cual aparece en el comentario de Langer, resulta una afirmación poco convincente, ya que se inspira en las diferencias entre las leyendas mitológicas y los cuentos, pero obvia los aspectos que los dos géneros tienen en común. Naturalmente, no cabe duda de que no se pueden igualar la evasión de la realidad que descubrimos en los cuentos de hadas y la de los mitos. Los cuentos suelen plasmar una visión utópica, mientras que las leyendas mitológicas reflejan el verdadero tejido de nuestras preocupaciones y desventuras. No obstante, no hemos de olvidar que en el plano estético el mundo ficticio de los mitos tiene muy poco que ver con nuestra realidad. Es decir, la acción se desarrolla en un espacio pululante con criaturas sobrenaturales, donde suceden cosas que nunca serían posibles en la vida real -por ejemplo, toda una cadena de transformaciones fantásticas como la fusión de sangre de Adonis y lágrimas de Venus convertida en anémonas o Dafne en laurel. Así, por sí mismo este tipo de leyendas nos aleja de los problemas cotidianos, dado que nos transporta a una tierra desconocida, fabulosa, intrigante. Aunque, como Langer afirma, el mito refleja el verdadero drama universal sin embellecerlo con una felicidad utópica, veo imprescindible observar que el efecto que tiene sobre nuestros propios miedos y problemas introducidos en un ambiente fantasmagórico es mucho menos doloroso que verlos plasmados en una obra que se basa en las imágenes que representan nuestra cotidianeidad. Esto se puede explicar de la siguiente manera: si los que tienen que encarar las dificultades son criaturas irreales, las propias dificultades también se contagian del aura ilusoria de la historia, es decir, se interpone una distancia psíquica considerablemente grande entre ellas y el hombre. En este caso, el mito ayuda a trasladar el miedo y la pesadumbre a una dimensión ficticia y, al menos por unos momentos, ellos se ven menos palpables.

También existe otra circunstancia relevante a la hora de hablar sobre la mitología como escape, y esta es la promesa de la eternidad que late en ella. Los personajes humanos de la narración mitológica suelen vivir en un espacio habitado por dioses donde las leyes terrenales se infringen constantemente; las deidades muchas veces tienen hijos con mortales, de esta manera transmitiendo algo de sus genes de la perennidad a la raza humana, por no mencionar que los propios dioses mueren y resucitan como Dioniso o migran entre el inframundo y la vida terrestre como Proserpina. Por consiguiente, inmersos en la temática mitológica nos hallamos en presencia de la eternidad como una condición existencial inevitable. Las líneas entre lo efímero y lo perpetuo se borran casi por completo. En otras palabras, nos sentimos

11 En la introducción de The Anthropological Structures of the Imaginary (Brisbane: Boombana Publications, [1992] 1999) Gilbert Durand resume este complejo vínculo entre la condición humana y la mitología así: «By myth we understand a dynamic system of symbols, archetypes and schemata which, under the impetus of a schema, tends to be composed into a story. Myth is already a first rationalisation since it uses the connecting thread of discourse, in which symbols are resolved into words, and archetypes into ideas» (62). 
menos vulnerables en un contexto donde la existencia de la vida del más allá se enuncia con una confianza absoluta. Y por añadidura, el hincapié en la omnipotencia del destino que rige las vidas de cada uno lleva otro efecto oculto: quita una parte de la responsabilidad de las acciones humanas y en cierto modo aplaca la conciencia, puesto que, si todo está determinado por los antojos de las fuerzas superiores representadas en los mitos como deidades, unas veces justas y prudentes, otras algo infantiles y ambiciosas, ¿queda acaso mucho en este mundo que dependa de nosotros?

Por lo dicho anteriormente podría deducirse que el mito aspira a la comprensión de la naturaleza de nuestras experiencias reales o, como observa Erich Bethe en su estudio llamado Mythus - Sage - Märchen: «Myth is primitive philosophy, the simplest presentational form of thought, a series of attempts to understand the world, to explain life and death, fate and nature, gods and cults ${ }^{12} \gg$. Sin embargo, no se nos debería escapar el hecho de que el sofisticado sistema estético del que presumen las leyendas mitológicas también ayuda al hombre a alejarse de sus preocupaciones trasladándolas a los personajes ficticios, pero sin ignorarlas u olvidarse de ellas por completo -lo que, en cambio, podría pasar con los cuentos de hadas.

\section{RECURSOS MITOLÓGICOS EN ÍCARO Y DÉDALO}

Ícaro y Dédalo, de Fernández de León, como comenta D. Becker, «se inspira en el modelo de doble argumento conocido desde Calderón, Solís y Diamante ${ }^{13}{ }^{\prime}$. San Emeterio complementa su afirmación señalando que «ello constituía una novedad en nuestro autor, que hasta ahora había limitado sus tramas a uno solo ${ }^{14} \gg$. En el caso de Ícaro y Dédalo el doble argumento aúna la famosa leyenda sobre la trágica muerte de Ícaro con la historia de Leda y Júpiter. Con el fin de analizar la influencia de la temática mitológica de la zarzuela en la conexión emocional entre el espectador y la obra, veo lo más preciso seguir con la metodología establecida en mi susodicho artículo, donde explico que entre los aspectos del concepto de distancia psíquica más relevantes en el análisis de la zarzuela áurea se hallan los grados distanciales y las digresiones de la actitud estética determinadas por una distancia psíquica excesiva o insuficiente ${ }^{15}$. Por lo tanto, el presente estudio se centrará en el tratamiento de la materia mitológica en la elaboración del argumento, los personajes y los símbolos de la obra.

12 Citado por Langer, Philosophy in a New Key, 144.

${ }^{13}$ Citado por Fernández San Emeterio, Melchor Fernández de León: la sombra de un dramaturgo (Madrid: Iberoamericana, 2011), 76.

${ }^{14}$ Ibidem, 77.

${ }^{15}$ I. E. Rozenbergaite, "La distancia psíquica como herramienta para analizar el teatro musical del Siglo de Oro“, 36-41. 


\section{EL CRUCE DE LOS MITOS}

En la versión del mito en la zarzuela de Fernández de León, después de huir en barco de $\mathrm{Creta}^{16}$, Dédalo, su hijo Ícaro y Libia, la amante del joven, llegan a una isla donde se le encarga a Dédalo construir dos torres: una «para encerrar a Leda y otra donde se les encierra a él y a su hijo ${ }^{17}$ ». Aquí se produce el «cruce con el mito de Leda», descrito por Fernández San Emeterio como «uno de esos mitos-imagen que, como el de Endimión, tenían tan poco argumento que servían casi para cualquier ocasión ${ }^{18}{ }_{\text {». El }}$ segundo mito, además, se suplementa con los rasgos de la leyenda de otra amada de Júpiter: Dánae. Fernández San Emeterio lo comenta así:

De este modo, sin jamás romper del todo con las fuentes clásicas, el dramaturgo, tal vez con el auxilio de algún erudito, hila un mito nuevo desarrollado según los cánones de la fiesta cortesana y cercano a lo que K. Sabik ha llamado «la problemática segismundiana» en la figura de Leda, encerrada, como el protagonista de La vida es sueño, en este caso para cumplir con el mandato de un oráculo ${ }^{19}$.

En la obra de Fernández de León Ícaro se enamora de Leda, la hija del rey Tíndaro, y así enfurece a Júpiter, el cual también la desea, de este modo potenciando una cadena de momentos rebosantes de celos y rivalidad. Naturalmente, la historia culmina con la muerte de Ícaro, quien fallece en las olas del mar, ya que el sol derrite la cera con la que están fijadas las plumas de las alas hechas por su padre. María Teresa Morabito subraya las grandes diferencias que existen entre la caída de Ícaro narrada por Ovidio y su versión en la zarzuela: mientras que en Las metamorfosis el joven muere en el intento de huir de Creta, en la obra de Fernández de León el suceso se moldea para «introducir un nuevo elemento, indispensable en la comedia del Siglo de Oro: el amor $^{20} \gg$. La estudiosa explica:

Ícaro sufre penas de amor por Leda hasta tal punto que llega a perder la razón; su locura lo lleva a querer arrojarse de la torre, y su padre, preocupado por su hijo, le construye las alas para que pueda alcanzar a su enamorada. La intervención del celoso Júpiter provoca la tragedia [...] Es Júpiter, al final de la comedia, quien hace que las plumas de Ícaro se despeguen en una escena de gran efecto espectacular ${ }^{21}$.

Aquí se debería aclarar que, efectivamente, el causante de la muerte de Ícaro son los celos de Júpiter, sin embargo, el castigo del dios se efectúa con la ayuda del ardiente orbe del sol: «En medio del teatro, en lo superior de él se descubre Júpiter en

\footnotetext{
${ }^{16}$ Fernández San Emeterio observa que en la zarzuela la huida de Atenas «no tiene el carácter vergonzoso que frecuentemente se le atribuía en la Antigüedad, pues es en defensa propia y de un arquitecto rival» (op. cit., 76).

${ }^{17}$ Ibidem.

${ }^{18}$ Ibidem, 76-77.

${ }^{19}$ Ibidem, 77.

20 María Teresa Morabito, "El tema de la caída en el Siglo de Oro“, AISO. Actas IV (2002), 1364.

${ }^{21}$ Ibidem.
} 
un sol [...] Empiezan a desunirse algunas plumas, y caer en el tablado ${ }^{22}$ ». Sin embargo, precisamente en esta variante del mito Júpiter declara haber convertido a Ícaro en astro y haber dado una especie de eternidad al joven.

Como podemos ver, a pesar de conservar los elementos esenciales de los mitos seleccionados -aparte de la famosa caída de Ícaro, cabe mencionar los símbolos del cisne y el oráculo ${ }^{23}$ - Ícaro y Dédalo no prescinde de numerosas inventivas por parte del autor. Sin embargo, como dice Reuben Brower, «there are no myths, only versions ${ }^{24} »$, es decir, el mito consiste en continuas interpretaciones que se adaptan a determinados contextos. Margaret R. Greer lo comenta así: «In reality, myths become static only when men no longer find them relevant to contemporary experience; while their meaning lives, they change, and every artistic rendering of the myth molds a new form ${ }^{25}$ ». De esta manera la estudiosa reivindica la autenticidad del mito que reside en la tendencia a experimentar con las archisabidas tramas mitológicas en las obras teatrales de los ingenios del Siglo de Oro.

\section{«SÍMBOLOS CARGADOS»}

Indudablemente, uno de los factores esenciales a la hora de emplear recursos mitológicos es su valor semántico. En este aspecto hemos de tener en cuenta que la mitología se puede calificar de "símbolo cargado» ("charged symbol"), un concepto inventado por Langer, que representa un símbolo que lleva numerosas connotaciones conocidas por el espectador ya antes de encontrarlo en determinado contexto. La filósofa da un ejemplo de la cruz que encarna el instrumento de la muerte de Cristo y, por consiguiente, el sufrimiento y la carga que lleva cada uno en sus hombros, además de ser un símbolo antiguo de zodíaco, un objeto artesano, etc. ${ }^{26}$. Pues muchos elementos mitológicos también se caracterizan por una multiplicidad de significados. Por ejemplo, el vuelo y la muerte de Ícaro, ampliamente conocidos incluso antes de ver la zarzuela de Fernández de León, igualmente destacan por una inmensa variedad de connotaciones: el propio vuelo y la muerte; una consecuencia triste de las ambiciones desmesuradas; las ansias de superar las limitadas capacidades humanas y liberarse de la complicada vida terrestre; los delirios de grandeza; la rebeldía; la atracción del riesgo; la fragilidad de la existencia y otros múltiples significados, marcados por lo que Durand denomina «negative valorisation of sudden movement ${ }^{27}$ ». Es decir, solo al oír el nombre de Ícaro, en la mente del espectador nace una cadena

22 Ibidem.

${ }^{23}$ La leyenda de Leda narra cómo Zeus -el equivalente griego de Júpiter-, transformado en cisne, se posa en la mujer y la embaraza. En el texto de Fernández de León, en cambio, el dios visita a Leda montado a un cisne, pero él mismo permanece en su forma humana. Mientras tanto, la función del oráculo proviene del mito de Dánae, pues esta, debido a un vaticinio, fue encerrada en una celda por su padre. En Ícaro y Dédalo es Leda quien se encuentra encarcelada en una torre a causa de un oráculo.

${ }^{24}$ Cit. por Margaret R. Greer en la ed. crit.: Pedro Calderón de la Barca, La estatua de Prometeo, 133.

${ }^{25}$ Ibidem.

26 Para una explicación más detallada de la noción de «símbolo cargado» véase: S. K. Langer, Philosophy in a New Key, 231-235.

${ }^{27}$ G. Durand, The Anthropological Structures of the Imaginary, 109. 
de imágenes, algunas entre ellas arquetípicas, que le causan la sensación de familiaridad, por ende, la afinidad del símbolo y su alma. Aquí se ha de añadir que el vuelo y la caída de Ícaro constituye una invariante, un término empleado por Jean Rousset ${ }^{28}$, que Carlos García Gual determina como «motivo que tiene una alusión icónica» y que constituye la estructura básica del mito, en otras palabras, aparece en todas las variantes del mito ${ }^{29}$. G. Durand relaciona la metáfora de la caída con los símbolos de la oscuridad y del alboroto, además, cita a Bachelard explica el fenómeno de esta manera: «... we imagine upward movement, and we know the downward fall ${ }^{30} \%$. Así que, podemos ver que al ser humano, debido a su experiencia vital, le cuesta menos interiorizar los símbolos vinculados con la caída que con la ascensión -hasta numerososo trastornos mentales suelen ser acompañados por visiones de la pérdida del equilibrio-. En este caso, queda claro que la imagen de la caída de por sí estimula una reducción de la distancia psíquica, lo que justifica de cierta manera la popularidad del mito de Ícaro.

Entre el resto de los «símbolos cargados» que abundan en el texto efectivamente, es poco probable que en una obra basada en argumentos mitológicos estos hagan falta- sobre todo descuellan el cisne, las torres, el barco, el mar, el sol, las alas y, finalmente, los propios Júpiter y Dédalo. El cisne, como es sabido, representa una gran variedad de significados y aparece en numerosas culturas: a menudo el símbolo se suele asociar con la pureza, la belleza y la gracia, que en el contexto cristiano puede implicar una alusión a la Virgen María; según las creencias celtas, el cisne aludía a la dimensión espiritual, al amor fiel, a la eternidad, a la transformación y mucho más; en la mitología china el símbolo se vinculaba con la luz y el sol; mientras que en los mitos grecolatinos este ave se conocía como acompañante de Venus y Apolo y, naturalmente, como una de las metamorfosis de Júpiter, por lo que el símbolo poseía varias semejanzas con las deidades mencionadas y también podía referirse al arte de la música; la poesía; la sabiduría; la dignidad; además, se caracterizaba por la dualidad sensorial, ya que encarnaba tanto la inocencia como el erotismo.

La torre a su vez implica un nexo entre la tierra y el cielo, aunque en numerosas ocasiones evidencia el fracaso del hombre y su ego a la hora de competir con la creación divina, sus ambiciones desmesuradas o la inestabilidad de su existencia-como ilustración podría servir la Torre de Babel, cuyo mito se narra en el Antiguo Testamento-. También son dignos de mencionar los siguientes significados del símbolo: la ascensión; los conocimientos de lo bueno y lo malo presentes en el discurso cristiano; la prisión o una carta de Tarot, la cual se relaciona con el caos y el desastre; el distanciamiento o la actitud de «contemplación monárquica» vinculada con las cimas altas que se comenta por Bachelard del siguiente modo: «Contemplation from a Summit gives a sense of sudden mastery over the universe. Ascensional acts and postures are naturally accompanied by a feeling of sovereignty ${ }^{31} »$. Tampoco deberíamos olvidar que en Ícaro y Dédalo aparece no una, sino dos torres, lo que oculta

${ }^{28}$ El mito de Don Juan, México, Fondo de Cultura Económica, 1985.

${ }^{29}$ Carlos García Gual ("Mitología y literatura en el mundo griego", Amaltea. Revista de mitocrítica, 0 (2008): 1-11), 5.

${ }^{30}$ G. Durand, The Anthropological Structures of the Imaginary, 109.

${ }^{31}$ Cit. por Durand en ibidem. 132. 
otro símbolo relevante en diferentes culturas: el número suele denotar la dualidad, la unión, un testimonio válido más de una vez mencionado en la Biblia o el amor romántico.

El barco, como afirma S. K. Langer, se sitúa entre los «símbolos cargados» más populares. Lo describe así:

A ship is [...] the image of precarious security in all-surrounding danger, of progress toward a goal, of adventure between two points of rest, with the near, if dormant, connotation of safe imprisonment in the hold, as in the womb. Not improbably the similar form of a primitive boat and of the moon in its last quarter has served in past ages to reinforce such mythological values ${ }^{32}$.

El mar, sin duda alguna, es otro de los «símbolos cargados» más frecuentes y polivalentes en la historia universal. Ofrece una escala de significados contrastivos: por un lado, el mar encarna el peligro y la índole imprevisible del destino -recordemos el complicado viaje de Ulises o a Leviatán, quien, según el Antiguo Testamento, acecha en las profundidades del mar-, refleja el caos, la destrucción, la naturaleza salvaje, pero, además, al símbolo se pueden atribuir significados totalmente contrarios: los mitos muchas veces solían asociar el fenómeno con los orígenes de la humanidad, la fertilidad, la abundancia, la perennidad y las fuerzas dinámicas. Durand se refiere al mar como «the supreme primordial swallowen» y explica que «The feminised, maternal abyss is, for numerous cultures, the archetype of the return to the original sources of happiness ${ }^{33} \gg$-el estudioso da ejemplo de la figura de Mama Cocha, la cual para las culturas incas representaba el mar y se consideraba la deidad más importante-. También se ha de tener en cuenta que el mar en sí implica una imagen de muy alto valor estético y presume de un fuerte efecto sensorial, lo que tiende a cautivar al hombre y establecer con este un vínculo psíquico bastante estrecho.

Naturalmente, otro elemento de suma importancia en Ícaro y Dédalo es el sol, que actúa como instrumento de castigo divino. El símbolo representa el poder supremo, los dioses, la energía vital, la luz, la justicia, el proceso de la creación, la plenitud, el ego, etc. Debido a la gran variedad de connotaciones relacionadas con el poder y la naturaleza única, en el Siglo de Oro la figura del sol con frecuencia se empleaba como metáfora del rey. En diversas culturas antiguas el sol se solía comparar con los pájaros, por ejemplo, los hindúes lo identificaban con el águila o el cisne. Durand, además, incide en la función purificadora que reside en el símbolo y lo describe como «the fire of elevation, sublimating everything exposed to its burning influence $\mathrm{e}^{34} \gg$.

Las alas, por otra parte, suelen ser un símbolo bastante uniforme, dado que probablemente en todas las culturas expresan la idea de libertad o las aspiraciones espirituales. Las ideas que transmite esta figura no son complicadas para adaptar a cualquier deseo humano, por lo que cada persona suele ver las alas como metáfora de

32 S. K. Langer, Philosophy in a New Key, 232.

${ }^{33}$ G. Durand, The Anthropological Structures of the Imaginary, 218.

${ }^{34}$ Ibidem, 168. 
sus propios anhelos íntimos ${ }^{35}$. Además, el significado positivo de la propia semántica del símbolo ejerce como anzuelo para atrapar la atención del hombre, hacerlo soñar y acordarse de sus propios objetivos, que exigen un fuerte impulso e inspiración. En este caso, me atrevo a suponer que las alas, al aludir a los deseos más profundos y sin llevar connotaciones claramente negativas - a pesar de que en determinados contextos y en la confrontación con otras figuras alegóricas el símbolo puede adquirir la significación de los sueños frustrados o algo por el estilo, siempre mantienen el núcleo semántico de «sueño», «deseo» o «aspiración»-, propenden a colarse en la subconsciencia del hombre acortando de esta manera la distancia psíquica entre él y el símbolo.

Tampoco se nos debería escapar el valor semántico que contienen las figuras de Júpiter y Dédalo. El primero, como padre de los dioses, representa el poder divino, la energía, la pasión carnal, la dominancia, la fuerza masculina, el furor, el despotismo o, en algunas ocasiones, incluso la justicia, mientras que el segundo encarna la sabiduría, el conocimiento, la maestría, la artesanía, la inspiración y la creación. Como podemos ver, los dos se podrían considerar como representantes del poder, aunque en distintos campos.

La relevancia que suelen tener los «símbolos cargados» en la recepción de una obra de arte es extraordinaria. Tienden a estimular distintas emociones relacionadas con la gran cantidad de ideas que transmiten y a alentar el pensamiento analítico, lo que hace el nexo entre el espectador y la obra más estrecho, más personal, en otras palabras, disminuye la distancia psíquica. Además, se ha de tener en cuenta que los conceptos simbolizados por los elementos mitológicos se emplean en las zarzuelas áureas de manera relativamente clara y genérica -no cuesta mucho notar que el sustrato que tiene la figura de Dédalo en la comedia de Fernández de León resulta considerablemente menos complicado y poliédrico que el que podemos encontrar en las famosas obras de James Joyce, A Portrait of the Artist as a Young Man y Ulysses-. Es decir, la simbología que aparece en Ícaro y Dédalo es tan ampliamente manejable que básicamente cada integrante del público puede evocar particulares momentos de su cotidianeidad que reflejen las ideas expresadas por la temática mitológica de la zarzuela, de este modo dándole colores de su propia vida -por no mencionar que siempre existía la posibilidad de elegir entre numerosas connotaciones por las que se caracterizaban los elementos mitológicos-. De ahí que, considerado el hecho de que el teatro musical áureo rebosaba de símbolos cargados de este tipo, se ha de observar que existía un señuelo bastante eficaz para que el espectador estableciera una conexión interna con la obra, sobre todo que no había necesidad de entrar en los detalles del símbolo para al menos ser capaz de captar algunos aspectos de su contenido.

${ }^{35}$ Citando a Bachelard, Durand afirma que el ala es «a symbolic mean of rational purification» $y$ añade: «The result of this is that paradoxically the bird is never envisaged as an animal, but rather as a simple accessory of the wing» (ibidem, 126). 


\section{LÍMITES CREATIVOS}

No obstante, el uso de la mitología para concebir argumentos de las zarzuelas igualmente destacaba por una fuerza distanciadora bastante potente en el plano del desapego artístico. Juan Luis González García comenta así el excesivo uso de las leyendas mitológicas en el Siglo de Oro: «Muchos optaron por no crear metáforas nuevas y se atuvieron a los clásicos, alternando y renovando las comparaciones que los antiguos habían utilizado [...] esas mismas auctoritates reprimieron la inventiva de los intelectuales ${ }^{36}{ } \%$. Esta práctica de idear textos para el teatro musical ciñéndose a los argumentos mitológicos - evidentemente, en el caso de los mayores maestros, con estilo personal bien marcado, pero todavía con la misma base temática- revela las restricciones creativas que tenían que afrontar los escritores y que impedían el nacimiento de obras originales, con tramas inesperadas y personajes no estereotípicos. También, queda claro que las situaciones convencionales en el teatro complacían al público del momento. Es decir, los espectadores estaban dispuestos a ver una y otra vez el mismo modelo de enredos, los mismos personajes y variaciones de los mitos archisabidos, aunque representados en distintos lenguajes poéticos. Por lo tanto, no queda más que admitir que el público no parece haber sentido mucha necesidad de novedades, sino que se adaptaba perfectamente a la restringida variedad de las tramas antiguas - una circunstancia que evidencia la práctica habitual en el teatro áureo donde el espectador solía asistir al desarrollo de una acción interesado, pero sin involucrarse demasiado.

Sin embargo, no deberíamos olvidar que en aquella época existía una fuerte censura que hasta cierto punto podía ser traspasada en el contexto mitológico, por ejemplo, en el caso del erotismo. Aunque Ícaro y Dédalo no se podría calificar como zarzuela que aluda mucho a los temas eróticos, al contrario de, por ejemplo, Los celos hacen estrellas de Juan Vélez de Guevara -en ella la ninfa Isis se ve involucrada contra su voluntad en una situación de adulterio- la aparición de Júpiter montado a un cisne en la zarzuela de Fernández de León consiste en una clara referencia a la historia de Leda, fecundada por el rey de los dioses transformado en cisne. Por encima de todo, esta llegada de Júpiter a la torre de Leda va acompañada por un parlamento del dios sobre su amor hacia la mujer, en el que un conocedor de tramas amorosas de Júpiter podría descubrir un mensaje erótico más: «pues mi amor penetrará aquella torre ${ }^{37}$ »una referencia a la leyenda de Dánae; esta fue encerrada en una celda por su padre, pero el rey del Olimpo consiguió alcanzarla convertido en lluvia dorada y la dejó

${ }^{36}$ Juan Luis González García, Imágenes sagradas y predicación visual en el Siglo de Oro, Madrid, Ediciones Akal, 2015, 24.

${ }^{37}$ Melchor Fernández de León, Ícaro y Dédalo, ed. Comedias nuevas, parte cuarenta y ocho. Escogidas de los mejores ingenios de España (Madrid: Bernardo de Villa-Diego, 1704 [1684]), 447-493 (470). Siento la necesidad de dar una explicación con respecto a la referencia a la cita en el libro indicando la página en vez de los versos: desafortunadamente, no existe una edición crítica de la obra, por lo que las indicaciones de las citas que, desde mi punto de vista, tienen más sentido son las que dirijan al lector a las páginas concretas. 
preñada. Por lo tanto, podemos ver que el subtexto erótico en Ícaro y Dédalo ilustra bien la tendencia común a esquivar la censura de la Iglesia en el arte del momento.

Otra función importante del argumento mitológico en nuestra zarzuela son ciertas intenciones pedagógicas comentadas con mucho acierto por Fernández San Emeterio, quien señala elementos aislados que parecen «estar apuntando hacia la actualidad, tanto cortesana como social ${ }^{38}$ » -entre ellos destaca «el parlamento inicial de Dédalo, que incluye una referencia a la necesidad de la educación en un noble ${ }^{39} \gg-$. No obstante, el estudioso rechaza la sugerencia de una lectura didáctica completa propuesta por Carmen Sanz Ayán: «En cuanto a la posible lectura pedagógica [...] no la creo unívoca ni completa, sino tal vez introducida al hilo de la trama y sin buscar demasiada profundidad en ella ${ }^{40}{ }$. Sea como sea, no queda duda de que el autor de Ícaro y Dédalo acertó a servirse con elegancia del fundamento mitológico para tratar ciertos asuntos bastante delicados en la época.

\section{ENTRE LO ABSTRACTO Y LO PERSONAL}

Aun consciente de la relativa libertad que daba este tipo de argumentos a los creadores de zarzuelas a la hora de introducir temas que no se podían comentar abiertamente, creo indispensable señalar que el carácter abstracto de los recursos mitológicos suponía un agente distanciador con respecto al involucramiento por parte del espectador. Los argumentos así condicionaron la inclinación a lo estereotipado, puesto que tanto los personajes provenientes directamente de las leyendas grecorromanas como los que encarnaban abstracciones y eran habituales acompañantes de los héroes antiguos en las obras teatrales -si no en la trama principal, al menos en las piezas breves que la enmarcaban, por ejemplo, la Hermosura, la Discreción, la Fama y la Duda, presentes en la loa de Ícaro y Dédalo- se caracterizaban por ser retratos de poca profundidad psicológica. Esto se debía parcialmente a la índole alegórica de las obras, ya que, como observa Molina Jiménez, en los dramas musicales «cada mito se convierte en la personificación de un vicio o una virtud ${ }^{41} »$. Naturalmente, los personajes también encarnaban ciertas pasiones, vicios o virtudes, lo que reflejaba claramente la tendencia al antiindividualismo y verdades estereotipadas. Como tenían que transmitir ciertos conceptos, los personajes no podían poseer cualidades alejadas del valor que representaban y esto no les dejaba adquirir caracteres complejos, polifacéticos ni revelar la confusión espiritual y variedad de matices individuales, en nuestros días muy valorados y normalmente hasta requeridos en el arte. Por ejemplo, todos conocían a Júpiter y a nadie le sorprendía verlo como encarnación de poder, autoridad y energía masculina en Ícaro y Dédalo ni en un sinnúmero de otras zarzuelas auriseculares, asimismo resultaba natural que Ícaro fuese una metáfora de la juventud rebelde, las ambiciones desmesuradas y el idealismo juvenil condenado a la desilusión,

${ }^{38}$ Fernández San Emeterio, Melchor Fernández de León: la sombra de un dramaturgo, 77.

${ }^{39}$ Ibidem, 78.

${ }^{40}$ Ibidem, 77.

${ }^{41} \mathrm{M}^{\mathrm{a}}$ B. Molina Jiménez, Literatura y música en el Siglo de Oro español. Interrelaciones en el Teatro Lírico, Tesis Doctoral, Depósito institucional de la Universidad de Murcia, 2005, 132. 
mientras que Leda cumplía perfectamente con el famoso modelo de una bella desdeñosa y deseada, quien al final de la obra bajaba la cabeza ante la voluntad del destino -en la comedia de Fernández de León Leda decide hacerse sacerdotisa del Sol con el propósito de dar a luz a Cástor y Pólux, una explicación cuya «resonancia cómica», según Fernández San Emeterio, «no es menester explicarla ${ }^{42}$ ».

Lo mismo pasaba con los argumentos que, a pesar de numerosas digresiones de Ovidio u otras fuentes clásicas, solían conservar muchas semejanzas con los sucesos en las leyendas en las que se inspiraban: todos tenían claro que Ícaro no podría terminar de otra manera que la épica caída con las alas construidas por su padre; tampoco era difícil predecir que Leda se resignaría al destino de tener hijos de Júpiter y que el rey de los dioses saldría triunfante. De la misma manera se podían conocer con antelación y con bastante certeza los hitos básicos del viaje emocional de los personajes: no cabía duda de que Dédalo, después de una infinidad de preocupaciones, acabaría sumido en un dolor agonizante debido a la pérdida de su hijo, ni se podía esperar otra cosa por parte de Júpiter que una intensa cadena de explosiones de pasión, celos y agresividad en relación con el objeto de su deseo, Leda, y los pretendientes a su corazón. Además, resultaba fácil adivinar que Ícaro pasaría sus días regido por anhelos fervorosos, decisiones espontáneas y altas ambiciones. Por lo tanto, los héroes mitológicos distaban poco de los personajes que abiertamente representaban alguna virtud. Mientras tanto, la acción de la obra parecía ser pura alegoría.

En otras palabras, los caracteres de origen mitológico y sus acciones muchas veces carecían de la complejidad inherente a un ser humano, lo que impedía al espectador identificarse con ellos. Bullough observa que las abstracciones suelen provocar una gran distancia psíquica por su falta de conexión personal con el público, a no ser que adquieran un «dueño» y $e l$ amor, $e l$ temor, $e l$ patriotismo se conviertan en $m i$ amor, $m i$ temor, $m i$ patriotismo, etc. ${ }^{43}$ Una cosa semejante pasaba con numerosos personajes de las zarzuelas barrocas: si uno intentaba verlos como individualidades, la falta de complejidad los hacía inverosímiles, lo que aumentaba la distancia entre la obra y el espectador; tampoco hacía disminuir la distancia si uno los percibía como meras alegorías de conceptos abstractos como los celos, el amor, la rebeldía y otros. Sin embargo, si el espectador consideraba las pasiones representadas por los personajes alegóricos y mitológicos como reflejos de sus propias pasiones y empatizaba con Ícaro porque reconocía en él sus propios sueños frustrados o percibía en Júpiter un eco de su propio deseo, la distancia podía ser disminuida hasta el punto de desaparecer del todo. Además, existía el factor de la familiaridad, puesto que la mayoría de los personajes eran bien conocidos y aparecían en muchas obras - por ejemplo, Júpiter se encontraba en dos zarzuelas de mucho éxito situadas en un marco temporal de dos años, Júpiter y Semele (1670), de Juan Bautista Diamante, y Los celos hacen estrellas (1672), de Juan Vélez de Guevara y lo que los hacía similares a los caracteres de las series actuales cuando uno ya se acostumbra a observar su vida en distintos capítulos, y esto

${ }^{42}$ Fernández San Emeterio, Melchor Fernández de León: la sombra de un dramaturgo, 83.

${ }^{43}$ Véase: E. Bullough, "Aesthetic Distance as a Factor in Art and an Aesthetic Principle", British Journal of Psychology, 5 (1912), 87-117. 
igualmente implica una distancia disminuida ${ }^{44}$. Por lo tanto, el manejo de la distancia en los argumentos mitológicos resultaba un proceso complicado y contrastivo; sin embargo, el espectador estaba acostumbrado a él.

Esta tendencia a evitar la creación personal completamente original en los argumentos de las obras músico-teatrales, igual que la renuencia a crear nuevos símbolos y a someter al público a un análisis profundo y complejo de la vida espiritual, evidencia una especie de cansancio emocional del que padecía la sociedad europea en la agitada época del Barroco, ya que era mucho más fácil observar las acciones de unos personajes esquemáticos que profundizar en fuentes más turbias del mundo interior de una personalidad complicada e impredecible, a través de cuyo análisis al espectador resultaría imposible evitar sus propias confusiones espirituales. Por otro lado, no se nos debería olvidar que la mitología, siendo sistema de símbolos ampliamente conocidos, se podía aprovechar como señuelo para captar la atención del público y acelerar el proceso de su involucramiento psíquico en la representación, aunque podía provocar un desapego emocional igual de repentino por la falta de factor sorpresa en la trama y las características de los personajes.

\section{CONCLUSIONES}

Desde la perspectiva de la distancia psíquica el manejo de los recursos mitológicos en la zarzuela áurea constituía un fenómeno ambivalente que conllevaba tanto el polo distanciador como acercador. En otras palabras, se caracterizaba por un influjo bastante ambiguo en el nexo emocional entre el espectador y la obra. El caso de Ícaro y Dédalo nos deja ver que la mitología, constituida por «símbolos cargados», servía para suscitar la sensación de familiaridad en la mente del espectador vía una abundancia de imágenes mentales producidas por la polisemia de sus símbolos -p. ej., el vuelo y la caída de Ícaro, el cisne o el mar-, y así solía trabar un vínculo estrecho con el público disminuyendo la distancia psíquica en alto grado. Asimismo, de manera acercadora funcionaban los personajes conocidos que aparecían en distintas obras -p. ej. Júpiter en Los celos hacen estrellas y Júpitery Semele-, de ahí que el público ya tenía cierta actitud hacia ellos formada durante un tiempo. No obstante, la falta de dinámica de la base argumental y el uso excesivo de abstracciones, en gran parte condicionado por el predominio de la materia mitológica en la obra, produjo el efecto de desindividualización y la carencia de profundidad psicológica -pero de ninguna manera filosófica- en los retratos de los personajes.

En este caso existían tres variantes de la actitud por parte del espectador: este podía intentar ver a esos personajes como individualidades, pero muchas veces la

${ }^{44}$ C. García Gual ("Mitología y literatura en el mundo griego") señala la importancia de los personajes que salen en numerosos mitos como una de las diferencias esenciales entre las leyendas mitológicas y los cuentos de hadas: «Esta definición de mitología como red de relatos sirve también para distinguir los mitos de los cuentos, en el sentido de cuentos fantásticos (como cuentos populares...). Los cuentos tienen muchas veces los mismos motivos que los mitos, pero van sueltos, y los personajes no suelen tener nombre, mientras que los personajes de los mitos siempre tienen nombre y se pueden colocar dentro de esa red mítica...» (3). 
escasez de complejidad los hacía inverosímiles, lo cual, indudablemente, aumentaba la distancia psíquica; además, era posible verlos como meras abstracciones -p. ej., Júpiter como encarnación de poder y energía masculina o Ícaro como símbolo de rebeldía juvenil y ambiciones desmedidas-, mas esto tampoco ayudaba a disminuir la distancia; y, finalmente, uno podía considerar las pasiones representadas por los personajes alegóricos y mitológicos como reflejos de sus propias pasiones, lo que corría el peligro de provocar una pérdida de distancia total.

Asimismo, la mitología, entendida como sistema metafórico orientado a reflejar el drama universal, tendía a resonar fuertemente en el alma del espectador, dado que sus símbolos constituían un recordatorio de las preocupaciones cotidianas y esto servía como otro agente importante para acortar la distancia, aunque igualmente amenazaba con su posible pérdida, mientras que su estética fantasmagórica funcionaba como una especie de lastre para disminuir el realismo de los problemas mostrados en la obra para que el espectador los perciba de manera menos personal. Por ende, la base mitológica representaba muchos riesgos de digresiones distanciales, las cuales obstaculizaban la permanencia ininterrumpida de la actitud puramente estética por parte del público durante la representación.

Así pues, la tendencia a evadir la individualidad y un análisis complejo de la vida espiritual, que transparenta el tratamiento de la base mitológica en las zarzuelas, evidencia que la sociedad europea del momento padecía una fatiga crónica, puesto que observar las acciones de los personajes esquemáticos requería mucho menos esfuerzos intelectuales y emocionales que ahondar en las facetas más complejas del mundo interior capaces de excavar las propias confusiones espirituales del espectador. Sin embargo, el fuerte carácter filosófico del mito traslucía la necesidad del hombre de organizar en su mente ciertas ideas del orden universal sin que estas conmoviesen demasiado sus adentros, mientras que la impresionante estética del mundo de las leyendas mitológicas denotaba las ganas de escapar, envolverse en el velo mágico y sentirse protegido por el aura de la eternidad que latía en ella al menos por unos breves momentos. 


\section{REFERENCIAS BIBLIOGRÁFICAS}

Bullough, Edward, "Aesthetic Distance as a Factor in Art and an Aesthetic Principle", British Journal of Psychology, 5 (1912): 87-117.

Campbell, Joseph. The Hero with a Thousand Faces (New Jersey, Princeton University Press, [1949] 2004).

(en colab. Bill Moyers). The Power of Myth (EE. UU., Anchor Edition, [1988]1991).

Díez Borque, José María, Sociología de la comedia española del siglo XVII (Madrid, Cátedra, 1976).

Sociedad y teatro en la España de Lope de Vega (Barcelona, Antoni Bosch, 1978).

Historia del teatro en España, Tomo I, Edad Media, Siglo XVI, Siglo XVII (Madrid, Taurus Ediciones, 1983).

Domínguez Ortiz, Antonio, La sociedad española en el siglo XVII (Universidad de Granada, vol. 2, 1992).

Durand, Gilbert, The Anthropological Structures of the Imaginary (Brisbane: Boombana Publications, [1992] 1999).

Fernández de León, Melchor, Ícaro y Dédalo, ed. Comedias nuevas, parte cuarenta y ocho. Escogidas de los mejores ingenios de España (Madrid, Bernardo de Villa-Diego, ([1684] 1704): 447-493.

Fernández San Emeterio, Gerardo, Melchor Fernández de León: la sombra de un dramaturgo. Datos sobre vida y obra (Madrid, Iberoamericana, 2011).

García Gual, Carlos, "Mitología y literatura en el mundo griego", Amaltea. Revista de mitocrítica, 0 (2008): 1-11.

González García, Juan Luis, Imágenes sagradas y predicación visual en el Siglo de Oro (Madrid, Ediciones Akal, 2015).

Langer, Susanne K., Philosophy in a New Key (Harward University Press, [1948] 1954).

Feeling and Form (Charles Scribner's Sons New York, 1953).

Maravall, José Antonio, Teatro y literatura en la sociedad barroca (Barcelona, Editorial Crítica, [1972] 1990). 
La cultura del Barroco (Barcelona, Ariel, 1998).

Molina Jiménez, Ma Belén, "Literatura y música en el Siglo de Oro español. Interrelaciones en el Teatro Lírico" (Tesis Doctoral, Depósito institucional de la Universidad de Murcia, 2005).

Morabito, María Teresa, "El tema de la caída en el Siglo de Oro" (AISO. Actas VI, 2002) 47-52.

Odin, Steve, Artistic Detachment in Japan and the West: Psychic Distance in Comparative Aesthetics (University of Hawaii Press, 2001).

Reiss, Timothy, "Psychical Distance and Theatrical Distancing in Sartre's Drama“, Yale French Studies, 46 (Yale University Press, 1971): 5-16. https://www.jstor.org/stable/2929602?seq=1 (consultado el 26 de julio de 2020). https://doi.org/10.2307/2929602

Rich Greer, Margaret, ed. crit., La estatua de Prometeo (Kassel Edition Reichenberger, 1986).

Rozenbergaite, Ieva Emilija, "La distancia psíquica como herramienta para analizar el teatro musical del Siglo de Oro", Diablotexto Digital, 7 (Universitat de València, 2020): 33-53. https://ojs.uv.es/index.php/diablotexto/article/view/16718/15497 $\begin{array}{llllll}\text { (consultado el } & 26 & \text { de julio } & \text { de } & \end{array}$ https://doi.org/10.7203/diablotexto.7.16718

Sabik, Kazimierz, "El tema del amor en los dramaturgos cortesanos de la escuela de Calderón", en: Atti del XX Convegno di Associazione Ispanisti Italiani, coord. Domenico Antonio Cusato, Loretta Frattale, vol. 1, (2002): 287-296.

Vélez de Guevara, Juan, Los celos hacen estrellas, ed. John E. Varey, Normand D. Shergold y Jack Sage (Londres, Tamesis Books Limited, [1672] 1970).

Recibido: 29 de septiembre de 2020

Aprobado: 13 de octubre de 2020 